\title{
ANÁLISE SOBRE A APLICABILIDADE DA AVALIAÇÃO AMBIENTAL ESTRATÉGICA NA CONSECUÇÃO DO DESENVOLVIMENTO SUSTENTÁVEL
}

\section{ANALYSIS OF STRATEGIC ENVIRONMENTAL ASSESSMENT OF THE APPLICABILITY IN ACHIEVING SUSTAINABLE DEVELOPMENT}

\begin{abstract}
Maria Claudia Silva Antunes de Souza
Doutora e Mestre em Derecho Ambiental y de la Sostenibilidad pelaUniversidade de Alicante - Espanha. Mestre em Ciência Jurídica pelaUniversidade do Vale do Itajaí - UNIVALI. Professora no Programa dePós-Graduação Stricto Sensu em Ciência Jurídica, nos cursos de Doutoradoe Mestrado em Ciência Jurídica, e na Graduação no Curso de Direito daUniversidade do Vale do Itajaí - UNIVALI. mclaudia@univali.br

JÉSSICA LOPES FERREIRA BERTOTTI Acadêmica do curso de Direito UNIVALI/SC. Integrante do Grupo de Pesquisa eExtensão Paidéia do CNPQ. jessicalfbertotti@gmail.com
\end{abstract}

\begin{abstract}
RESUMO
Entende-se a Avaliação Ambiental Estratégica (A.A.E.), como um instrumento pouco implementado na proteção do Meio Ambiente no Brasil. Sendo assim, o objeto da presente pesquisa é o incentivo do uso do conhecimento nacional acerca da AAE, como instrumento ao desenvolvimento sustentável. Obtevese como objetivo ANALISAR as possibilidades e limites da $A A E$ e da sua inclusão no ordenamento jurídico brasileiro, contribuindo para o desenvolvimento sustentável da região. Quanto ao referencial metodológico utilizou-se o método indutivo na fase de investigação. Concluiu-se pela viabilidade da implementação deste modo de planejamento e gestão que visam prevenir danos por meio de uma macro articulação, em que os agentes trabalham de maneira coordenada visando a proteção da área ambiental em que se quer pôr em prática, plano, programa ou política.
\end{abstract}

Palavras-chave: Avaliação Ambiental Estratégica (AAE); Desenvolvimento Sustentável; Meio Ambiente.

\begin{abstract}
It is understood that the Strategic Environmental Assessment (A. E.), as an instrument which is implemented to protect the Environment in Brazil. Thus, the object of this research is the encouragement of the use of national knowledge about the AAE, as an instrument for sustainable development. It is aimed to analyze the possibilities and limits of the EFA and about the inclusion in the Brazilian legal system, contributing (collaborating) to the sustainable development of the region. As the methodological framework used was the inductive method in the investigation period. It was concluded that the feasibility of the implementation of this mode of planning and management that are intended to prevent damage by means of a macro linkage, wherein agents work in a coordinated manner in order to protect the environmental area, which want to implement, plan, program or policy.
\end{abstract}

Keywords: Strategic Environmental Assessment (SEA); Sustainable Development; Environment. 


\section{SUMÁRIO}

INTRODUÇAO; 1. QUANTO À CONCEITUAÇÃO DA CATEGORIA AVALIAÇÃO AMBIENTAL ESTRATÉGICA; 2. QUANTO À CONCEITUAÇÃO DA CATEGORIA DESENVOLVIMENTO SUSTENTÁVEL; 3. COM RELAÇÃO AOS PRINCIPAIS ASPECTOS JURÍDICOS DO INSTITUTO DA AVALIAÇÃO DE IMPACTO AMBIENTAL E ESTUDOS DE IMPACTO AMBIENTAL; 4. A AVALIAÇÃO AMBIENTAL ESTRATÉGICA COMO MODELO DE GESTÃO E SEUS REFLEXOS NO CONTEXTO SOCIAL; 5. ANÁLISE DA VIABILIDADE DE IMPLEMENTAÇÃO NO ORDENAMENTO JURÍDICO BRASILEIRO DA AVALIAÇÃO AMBIENTAL ESTRATÉGICA; CONCLUSÃO; REFERÊNCIAS.

\section{INTRODUÇÃO}

Tendo-se em vista as estruturas atuais, novo paradigma surgiu em face da crise ambiental, fazendo despontar o ideal de desenvolvimento sustentável, o qual tem repercutido na seara global contemporânea. ${ }^{1}$

Fala-se então em compatibilizar meio ambiente com desenvolvimento significa considerar os problemas ambientais dentro de um processo contínuo de planejamento, atendendo-se adequadamente às exigências de ambos e observando-se as suas inter-relações particulares em cada contexto sociocultural, político, econômico e ecológico, dentro de uma dimensão de tempo/espaço. Isto é o ideal considerado de Desenvolvimento Sustentável. ${ }^{2}$

Nesse contexto faz-se importante entender que a Sustentabilidade consiste no pensamento de capacitação global para a preservação da vida humana equilibrada, consequentemente, da proteção ambiental, mas não só isso, também da extinção ou diminuição

\footnotetext{
Artigo elaborado relacionado à Bolsa Pesquisa ProBIC da Univali - Universidade do Vale do Itajaí, edital 2014/2.

${ }^{* * *}$ Authored Article related to Scholarship Search the ProBIC Univali - Universidade do Vale do Itajaí, notice 2014/2.

${ }^{1}$ Serão inseridas no decorrer deste primeiro tópico trechos que possuem contribuição direta com o tema tratado, com fundamento em parte do artigo científico apresentado e publicado em anais de evento do XXII Encontro Nacional do CONPEDI. Souza, Maria Claudia da Silva Antunes de. MAFRA, Juliete Ruana. A sustentabilidade e seus reflexos dimensionais na avaliação ambiental estratégica: $O$ ciclo do equilíbrio do bem estar. Disponível em: <http://www.publicadireito.com.br/artigos/?cod=ec82bd533b0033cb> Acesso em: set. de 2014.

${ }^{2}$ Souza, Maria Claudia da Silva Antunes de. MAFRA, Juliete Ruana. A sustentabilidade e seus reflexos dimensionais na avaliação ambiental estratégica: 0 ciclo do equilíbrio do bem estar. Disponível em: <http://www.publicadireito.com.br/artigos/?cod=ec82bd533b0033cb> Acesso em: set. de 2014. p. 196.
} 
de outras mazelas sociais que agem contrárias a esperança do retardamento da sobrevivência do homem na Terra. ${ }^{3}$

Alguns empecilhos teóricos devem ser superados para que se alcance efetivo entendimento, um desses empecilhos são as diferenças entre Sustentabilidade e Desenvolvimento Sustentável afloram com um processo em que a primeira se relaciona com o fim, enquanto o segundo com o meio. O Desenvolvimento Sustentável como meio para que seja possível obter equilíbrio entre o progresso, a industrialização, o consumo e a estabilidade ambiental, como objetivo a Sustentabilidade e o bem estar da sociedade. ${ }^{4}$

Quanto à evolução da ideia de sustentabilidade tem-se que até o início da década de 1970, o pensamento mundial dominante era no sentido de que o meio ambiente seria fonte inesgotável de recursos e que qualquer ação de aproveitamento da natureza não haveria fim. Entretanto, fenômenos como secas, chuva ácida e a inversão térmica alertaram o meio social, fazendo com que essa visão ambiental começasse a ser questionada. ${ }^{5}$

Passou-se o tempo, o cenário do meio ambiente por conta das impensadas degradações, teve como resultado em 2000, uma análise da ONU, onde a mesma estabeleceu 8 Objetivos do Milênio (ODM), que no Brasil são chamados de 8 Jeitos de Mudar o Mundo, os quais deveriam ser atingidos por todos os países até 2015. São eles:

Objetivo 1, erradicar a pobreza extrema e a fome; objetivo 2, atingir o ensino básico universal; objetivo 3 , promover a igualdade entre os sexos e a autonomia das mulheres; objetivo 4 , reduzir a mortalidade infantil; objetivo 5 , melhorar a saúde materna; objetivo 6, combater o HIV/AIDS, a malária e outras doenças; objetivo 7 , garantir a sustentabilidade ambiental; objetivo 8 , estabelecer uma parceria mundial para o desenvolvimento. ${ }^{6}$

\footnotetext{
${ }^{3}$ SOUZA, Maria Cláudia da Silva Antunes de Souza. 20 anos de sustentabilidade: reflexões sobre avanços e desafios. Revista da Unifebe. 2012; 11 (dez): 239-252. Disponível: http://www.unifebe.edu.br/revistaeletronica/. Acesso em julho de 2014.

${ }^{4}$ Souza, Maria Claudia da Silva Antunes de. MAFRA, Juliete Ruana. A sustentabilidade e seus reflexos dimensionais na avaliação ambiental estratégica: O ciclo do equilíbrio do bem estar. Disponível em: <http://www. publicadireito.com.br/artigos/?cod=ec82bd533b0033cb> Acesso em: set. de 2014. p. 197.

${ }^{5}$ SENADO FEDERAL. Da Conferência das Nações Unidas para o Meio Ambiente Humano, em Estocolmo, à Rio-92: agenda ambiental para os países e elaboração de documentos por Comissão Mundial sobre Meio Ambiente e Desenvolvimento. Revista em discussão. Disponível em: http://www.senado.gov.br/noticias/Jornal/emdiscussao/rio20/a-rio20/conferencia-das-nacoes-unidaspara- o-meio-ambiente-humano-estocolmo-rio-92-agenda-ambiental-paises-elaboracao-documentoscomissao- mundial-sobre-meio-ambiente-e-desenvolvimento.aspx. Acesso em: julho de 2014.

${ }^{6}$ IPEA. Objetivos do Milênio. Brasília. 2005. Disponível em: <http://www.objetivosdomilenio.org.br/> Acesso em: set. de 2014.
} 
ANÁLISE SOBRE A APLICABILIDADE DA AVALIAÇÃO AMBIENTAL ESTRATÉGICA NA CONSECUÇÃO DO DESENVOLVIMENTO SUSTENTÁVEL.

Maria Claudia Silva ANTUNeS de SOUZA JÉSSICA LOPES FERREIRA BERTOTTI

Vê-se no objetivo de número 7 , a preocupação já crescente com a realidade do Meio Ambiente. Sendo que, após isso, na Rio + 20 A Conferência das Nações Unidas sobre Desenvolvimento Sustentável, ocorrida no Rio de Janeiro, teve a missão de renovar compromissos com o Desenvolvimento Sustentável em meio a urgências ambientais, sociais, econômicas e políticas, entrando na definição de metas para evitar a degradação do meio ambiente. Tornou-se a "onda do medo", certificando os efeitos degradantes dos danos ambientais e confirmando a firme necessidade de medidas resolutivas eficazes em cuidado ao futuro do planeta. ${ }^{7}$

Deste modo, Maria Cláudia S. A. de Souza, nos elucida que conforme Gabriel Real Ferrer anuncia que: “Insisto, sabemos más o menos como relacionarnos com el medio ambiente, lo que no sabemos es como relacionarnos entre nosotros mismos". Ele complementa que: “Lo que no sabemos y sobre lo que precisamos un consenso mundial es cómo articular las interrelaciones sociales que nos permitan construir una sociedad global y sostenible". ${ }^{8}$

Assim, pior do que a relação humana para com o meio ambiente é a relacionamento do homem consigo, uma vez que chegando ao consenso coletivo da imprescindibilidade da preservação ambiental, o Desenvolvimento Sustentável, a Sustentabilidade, não se consegue articular gestão passível de tornar efetivas as medidas em prol destas finalidades. ${ }^{9}$

À partir desse cenário, entende-se como necessária a utilização de alguma ferramenta preventiva e pró meio ambiente, pois;

[...] cabe ao ser humano, por meio da gestão ambiental, a administração dos recursos ambientais, de forma a propiciar a reposição ao ciclo da matéria e o aproveitamento de energia, impossibilitando que ocorra a superação da capacidade de suporte de sistemas, tanto ecológicos, quanto sociais. ${ }^{10}$

\footnotetext{
${ }^{7}$ CENTRO DOM HELDER DE CONVENÇÕES. Gabriel Real Ferrer apresenta palestra sobre as dimensões da sustentabilidade. Disponível em: < http://www.ecossocioambiental.org.br/artigos/n-a/>. Acesso em: julho de 2014.

${ }^{8}$ Mais uma vez, nós sabemos mais ou menos como se relacionar com o meio ambiente, não sabemos é como se relacionar entre nós. 0 que não sabemos é que nós precisamos de um consenso global para articular as inter-relações sociais que nos permitam construir uma sociedade global sustentável (Tradução livre). FERRER, Gabriel Real. Sostenibilidad, Transnacionalidad y Trasformaciones del Derecho. In: SOUZA, Maria Cláudia da Silva Antunes de (Org.); GARCIA, Denise Schmitt Siqueira (Org.); FERRER, Gabriel Real [et. al]. Direito ambiental, transnacionalidade e sustentabilidade. Livro eletrônico. Modo de acesso: World Wide Web: <http://www.univali.br/ppcj/ebook> 1. ed. Itajaí: UNIVALI, 2013. p. 8.

${ }^{9}$ Souza, Maria Claudia da Silva Antunes de. MAFRA, Juliete Ruana. A sustentabilidade e seus reflexos dimensionais na avaliação ambiental estratégica: O ciclo do equilíbrio do bem estar. Disponível em: <http://www.publicadireito.com.br/artigos/?cod=ec82bd533b0033cb> Acesso em: set. de 2014. p. 201.

10 SILVA, Monica Maria Pereira. Gestão ambiental e desenvolvimento sustentável. 2009. Disponível em: <http://mercadoetico.terra.com.br/arquivo/gestao-ambiental-e-desenvolvimento-sustentável/> Acesso em: julho de 2014. p. 02.
} 
Sendo assim, a Gestão Ambiental deve ser pautada em dez eixos norteadores: 1. Observância da capacidade de suporte dos sistemas ecológicos e sociais; 2 . Fatores limitantes; 3. Sucessão ecológica; 4. Inter-relação e interconexões; 5. Princípio da precaução; 6. Respeito às diversas formas de vida; 7. Nova ética ambiental e social; 8. Solidariedade; 9. Economia ecológica; 10. Educação ambiental como instrumento de gestão ambiental. ${ }^{11}$

Entende-se então, que no Brasil, a Gestão Ambiental, é por vezes tratada como tendo um caráter corretivo, sendo que o ideal seria que houvesse incutida na gestão seu caráter preventivo.

Sendo que, este caráter preventivo é que faz com que a Avaliação Ambiental Estratégica seja tão importante. Afinal, em termos gerais, Ortolano e Shepherd conceituam a AAE como "a avaliação ambiental no planejamento estratégico e na formação de políticas". ${ }^{2}$

Ressalta-se a relevância da pesquisa com base no exposto e no desenvolvimento da pesquisa, ficando caracterizado a relevância social da mesma, bem como sua contribuição para a ciência jurídica.

Com base no exposto, obteve-se como objeto de pesquisa, a contribuição para melhoria da efetividade na proteção ambiental, por meio do estudo das possibilidades e limites da AAE no desenvolvimento sustentável. Sendo que partiu-se do seguinte problema de pesquisa: 0 que vem a ser $A A E$, e de que maneira e até que ponto a $A A E$ poderá contribuir para o melhoramento das práticas de gestão ambiental, tornando a tomada de decisões, com repercussão, de crescimento econômico, mais sustentáveis e eficientes, de forma a contribuir com o desenvolvimento Sustentável?

Além do mais, baseou-se no seguinte OBJETIVO GERAL: ANALISAR as possibilidades e limites da AAE e de sua inclusão no ordenamento jurídico brasileiro, por meio do estudo das práticas de gestão ambiental, a fim de tornar mais fácil o alcance eficiente do desenvolvimento sustentável, contribuindo para a qualidade de vida na região.

\footnotetext{
11 SILVA, Monica Maria Pereira. Gestão ambiental e desenvolvimento sustentável. 2009. Disponível em: <http://mercadoetico.terra.com.br/arquivo/gestao-ambiental-e-desenvolvimento-sustentável/> Acesso em: julho de 2014. p. 02.

12 ORTOLANO, L.; SHEPHERD, A. apud BUCKLEY, Ralf. Strategic environmental assessment for the new century. Fargo (ND EUA): The Press, 1998. p. 77-86. Disponível em: <http://ac.elscdn.com/S0195925596000716/1-s2.0-S0195925596000716-main.pdf?_tid=7d5beee0-21cc-11e5-871c-

00000aacb35d\&acdnat=1435959966_654031c38875861d6eef2d242d22a9cf>. Acesso em: julho de 2014. Tradução Livre extraída do artigo Souza, Maria Claudia da Silva Antunes de. MAFRA, Juliete Ruana. A sustentabilidade e seus reflexos dimensionais na avaliação ambiental estratégica: 0 ciclo do equilíbrio do bem estar. Disponível em: <http://www.publicadireito.com.br/artigos/?cod=ec82bd533b0033cb> Acesso em: set. de 2014. p. 198.
} 
Quanto aos OBJETIVOS ESPECÍFICOS baseou-se na IDENTIFICAÇÃO dos principais aspectos jurídicos que envolvem o instituto da Avaliação de Impacto Ambiental e do Estudo de Impacto Ambiental, além de INCENTIVAR o desenvolvimento sustentável, compreendendo sua importância e necessidade de efetividade, ainda AVALIAR as possibilidades e os limites de se utilizar o instrumento da AAE na Avaliação de Impacto Ambiental das atividades que causam degradação ambiental e repercutem o crescimento econômico.

Com relação ao REFERENCIAL METODOLÓGICO utilizou-se o na fase de investigação, o indutivo, na fase de tratamento de dados fez-se a utilização do método cartesiano. Foram acionadas as técnicas do referente, da categoria, dos conceitos operacionais, pesquisa bibliográfica e fichamento.

\section{QUANTO À CONCEITUAÇÃO DA CATEGORIA AVALIAÇÃO AMBIENTAL ESTRATÉGICA}

Com o intuito de promover a sustentabilidade, como forma de proteção aos impactos ambientais causados de maneira antecipada, temos a Avaliação Ambiental Estratégica, como alternativa de prevenção à possíveis danos, conforme Egler ${ }^{13}$

Uma simples definição para a Avaliação Ambiental Estratégica: é a de que representa o processo de avaliação ambiental de políticas, planos e programas, ditos PPP's. Provavelmente, devido ainda a sua novidade, poucas definições tem sido atribuídas ao processo de $\mathrm{AAE}$, diferentemente do que existe para o processo de Avaliação de Impacto Ambiental (AIA). No âmbito do presente texto a definição a ser utilizada para AAE é àquela utilizada por Sadler e Verheem (1996): "AAE é um processo sistemático para avaliar as consequências ambientais de uma política, plano ou programa, de forma a assegurar que elas sejam integralmente incluídas e apropriadamente consideradas no estágio inicial e apropriado do processo de tomada de decisão, juntamente com as considerações de ordem econômicas e sociais".

No mesmo viés, tem-se que Vieira ${ }^{14}$ ressalta que o Decreto Lei de $n^{\circ} 232 / 2007$, trata da importância da AAE, Onde no preâmbulo do referido decreto, encontra-se estabelecido que:

\footnotetext{
${ }^{13}$ EGLER, Paulo Cezar Gonçalves. Perspectivas de uso no Brasil do Processo de Avaliação Ambiental Estratégica. Brasília: Parcerias Estratégicas, 2001.

14 VIEIRA, Germano Luiz Gomes. Proteção ambiental e instrumentos de avaliação do Ambiente. Belo Horizonte: Arraes Editores, 2011. p. 78.
} 
A realização de uma avaliação ambiental ao nível do planejamento da programação garante que os efeitos ambientais são tomados em consideração durante a elaboração de um plano ou programa antes da sua aprovação, contribuindo, assim, para a adoção de soluções inovadoras mais eficazes e sustentáveis e de medidas de controle que evitem ou reduzam efeitos negativos significativos no ambiente decorrentes da execução do plano ou programa. Por outras palavras, os eventuais efeitos Ambientais negativos de uma determinada opção de desenvolvimento, passam a ser pesados numa fase que precede a avaliação de impacto ambiental de projetos já em vigor no nosso ordenamento.

Vê-se então, que a $A A E$, envolve ações e atores ou agentes. Sendo que as ações são aquelas preconizadas por políticas, planos e programas. Os atores ou agentes, são então, pessoas físicas ou jurídicas, de direito público ou privado, que as colocam em campo. É ainda importante esclarecer que; essa avaliação prévia, fundamenta-se nos princípios da precaução e prevenção. Precaver-se e prevenir, não constituem medidas generosas e aleatórias, porém, são jurídica e tecnicamente necessárias, indispensáveis, quando se trata do meio ambiente. ${ }^{15}$

Milaré $^{16}$, trata do fato de que a Avaliação Ambiental Estratégica e todos os procedimentos e instrumentos originários da Avaliação Integrada Ambiental, são originários da Política Nacional de meio Ambiente.

Conforme Granziera ${ }^{17}$, no Direito brasileiro contemporâneo, tem-se como regra a análise de cada empreendimento, caso a caso, sem uma visão geral, dos efeitos do conjunto. A Avaliação Ambiental estratégica, tem então como seu objeto, uma macro visão sobre políticas, planos e programas, verificando, portanto, os impactos de sua implementação e estabelecendo, à partir disso estratégias para a minimização de danos ao meio ambiente como um todo.

Então, para elucidar, tem-se como exemplo; o caso de companhia estadual de saneamento que deve cumprir um programa de implementação de estações de tratamento de esgoto em uma determinada região, seria desejável e necessário um estudo acerca do impacto do conjunto de obras, seus benefícios e externalidades negativas, as formas previstas para a disposição final do lodo do esgoto, ao invés de licenciamentos pontuais de cada sistema. ${ }^{18}$

Quanto à atuação da Avaliação Ambiental Estratégica no cenário global jurídico, tem-se, conforme Bastos ${ }^{19}$ que;

\footnotetext{
${ }^{15}$ MILARÉ, Édis. Direito do Ambiente. $9^{\circ}$ Ed. São Paulo: Revista dos Tribunais, 2014. p. 666.

${ }^{16}$ MILARÉ, Édis. Direito do Ambiente. $9^{\circ}$ Ed. São Paulo: Revista dos Tribunais, 2014. p. 667.

${ }^{17}$ GRANZIERA, Maria Luiza Machado. Direito Ambiental. Ed. $3^{\circ}$. São Paulo: Atlas. 2014. p. 417.

18 GRANZIERA, Maria Luiza Machado. Direito Ambiental. Ed. $3^{\circ}$. São Paulo: Atlas. 2014. p. 418.

${ }^{19}$ BASTOS, Diego do Nascimento. A Avaliação Ambiental Estratégica como Subsídio para o Planejamento do Setor de Turismo no Brasil: Uma Análise do Caso da Costa Norte Rio de Janeiro: UFRJ/COPPE, 2010.
} 
[...] a prática internacional tornou evidente a necessidade de se dar ênfase à antecipação dos efeitos das intervenções do homem no ambiente, possibilitando a percepção de que os processos de AA devem estar voltados para considerações cuidadosas do futuro. Conforme, Hidden, 2000.A variável ambiental torna-se, assim, cada vez mais indissociável do planejamento das atividades e intervenções necessárias ao desenvolvimento e assume uma importância crescente nos processos de tomada de decisão. [...]Desde a sua criação, a política ambiental americana (NEPA) previa a aplicação da AIA a planos, programas e projetos, caso pudessem afetar significativamente o ambiente. Foi justamente nos Estados Unidos que surgiram os primeiros exemplos de aplicação da AIA em uma escala anterior ao nível de projetos de desenvolvimento, quando passou-se a avaliar os impactos ambientais dos planos de uso do solo, ainda em 1970. Posteriormente, em 1981, o US Department of Housing and Urban Development - USHUD publicou um guia para orientar a aplicação do instrumento aos planos urbanísticos: The Areawide Environmental Impact Assessment: a Guidebook. Conforme, cita Partidário, 2006.

Com base nesse cenário, a partir do início da década de 1990, Partidário ${ }^{20}$ nos descreve que em alguns países, sempre que a avaliação dos impactos ambientais se dava nos níveis iniciais do processo de planejamento,

[...]era designada como Avaliação de avaliação de PPP, o vasto âmbito de aplicação da AAE, teria que ser claramente distinta da AIA de projetos de desenvolvimento, pois deveria se revestir de uma natureza estratégica, olhar para prazos mais longos, abandonar os detalhes e garantir uma perspectiva abrangente, ou seja, mudar de escala.

O mesmo autor supracitado, interpreta que a simples referência à AAE como processo de avaliação ambiental de políticas, planos e programas seria uma conceituação aceitável na literatura da década de 1990, mas demasiado simplista e insuficiente nos dias de hoje. A evolução da AAE é complexa e sua prática possibilita múltiplas interpretações. ${ }^{21}$

Observa-se que vários instrumentos e procedimentos de Avaliação Ambiental têm sido desenvolvidos, na perspectiva de efetivamente atender aos requisitos da prática da gestão do meio ambiente e Teixeira ${ }^{22}$ nessa mesma linha, traz a Avaliação Ambiental como um processo

\begin{tabular}{l}
\hline Dissertação de Mestrado. Orientador: Emilio Lèbre La Rovere \\
Dissertação (mestrado) - UFRJ/COPPE/Programa de Planejamento Energético, 2010 p. 57. Disponível em: \\
<http://www.ppe.ufrj.br/ppe/production/tesis/diego_bastos.pdf> Acesso em: fev. 2015. \\
20 PARTIDÁRIO, M. R. Conceitos, evolução e perspectivas da Avaliação Ambiental Estratégica. In: \\
Seminário de Especialistas em Avaliação Ambiental Estratégica na América Latina e na Formulação e \\
Gestão de Políticas. Santiago do Chile: Chile. p. 27. 2006. \\
21 PARTIDÁRIO, M. R. Conceitos, evolução e perspectivas da Avaliação Ambiental Estrateégica. In: \\
Seminário de Especialistas em Avaliação Ambiental Estrateégica na América Latina e na Formulação e \\
Gestão de Políticas. Santiago do Chile: Chile. p. 27. 2006. \\
22 TEIXEIRA, I.M.V. O uso da Avaliação ambiental estratégica no planejamento da oferta de blocos para \\
exploração e produção de petróleo e gás natural no Brasil: uma proposta. p. 302. Tese (Doutorado em
\end{tabular} 
genérico que inclui a Avaliação de Impacto Ambiental (AIA) de projetos, a Avaliação Ambiental Estratégica (AAE) de Políticas, Planos e Programas (PPP) e um conjunto amplo de metodologias de planejamento e avaliação de impacto, conforme explicita na figura presente em sua Tese, apresentada a seguir (Figura 2).

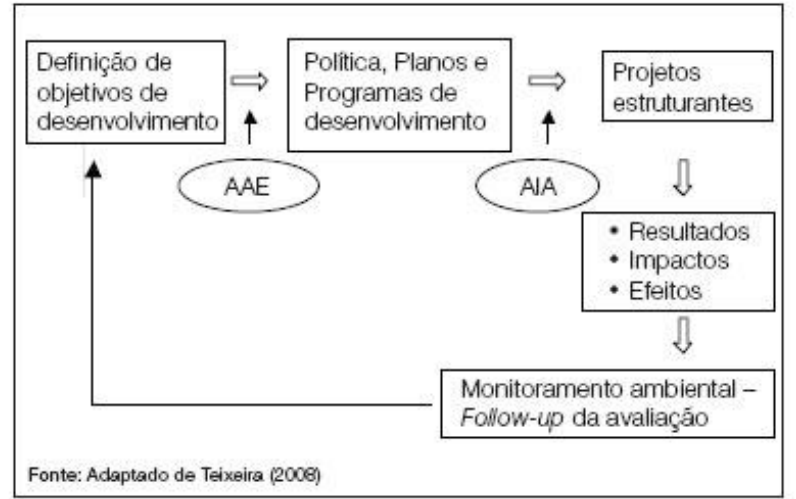

Figura 2 - Ciclo de políticas e a inserção de instrumentos de Avaliação Ambiental.

Além disso, com base nos autores Dalal e Sadler ${ }^{23}$, nota-se que o aparecimento do conceito de sustentabilidade como integrador da dimensão ambiental, social e econômica veio ampliar o debate sobre a abrangência da $A A E$, trazendo uma escala de referência mais compreensiva.

Sendo assim, a Avaliação Ambiental Estratégica, se diferencia das práticas de Gestão ambiental, pré existentes no brasil, pois traz uma abordagem de um planejamento e gestão que visam prevenir danos por meio de uma macro articulação, em que os agentes trabalham de maneira coordenada visando a proteção da área ambiental em que se quer pôr em prática, plano, programa ou política.

ciências em planejamento energético) - Universidade Federal do Rio de Janeiro, Rio de Janeiro. 2008. Disponível em: <http://ppe.ufrj.br/ppe/production/tesis/imvieira2.pdf> Acesso em: fev. de 2015.

${ }^{23}$ DALAL, Clayton, B.; SADLER, B., Strategic Environmental Assessment: A Sourcebook and Reference Guide to International Experience, London, Earthscan. 2005. Texto disponível em: <http://pubs.iied.org/pdfs/G02193.pdf> Acesso em fev. 2015. 


\section{QUANTO À CONCEITUAÇÃO DA CATEGORIA DESENVOLVIMENTO SUSTENTÁVEL}

Estamos passando pera Era do consumo exacerbado, e Capra ${ }^{24}$ em suas obras tenta nos esclarecer como pode haver uma humanização do desenvolvimento econômico, onde trabalha então a questão do Desenvolvimento Sustentável, e pensamento sistêmico, sendo que este pensamento nos traz que;

O universo material é visto como uma teia dinâmica de eventos interrelacionados. Nenhuma das propriedades de qualquer parte dessa teia é fundamental, todas elas resultam das propriedades das outras partes, e a consistência global de suas inter relações determina a estrutura de toda a teia.

Ressalva-se então, que olhar as questões ambientais como um todo, é praticar a Avaliação Ambiental estratégica e ter um pensamento sistêmico mais eficaz, para que se alcance a proteção ambiental.

O desenvolvimento sustentável tem como objetivo definir um modelo econômico capaz de gerar riquezas e bem estar, concomitantemente que fomente a coesão social e impeça a degradação do ambiente. ${ }^{25}$

Nesse sentido, Fiorillo diz que: considera-se o "Desenvolvimento Sustentável como o desenvolvimento que atenda às necessidades do presente, sem comprometer as futuras gerações". ${ }^{26}$

Segundo Freitas ${ }^{27}$, o Desenvolvimento Sustentável;

O princípio do desenvolvimento sustentável (ou da sustentabilidade, como se prefere), levado a bom termo, introduz gradativa e plasticamente, na sociedade e na cultura, um novo paradigma [...] o princípio constitucional da sustentabilidade estatui, com eficácia direta e imediata, em primeiro lugar, o reconhecimento da titularidade dos direitos daqueles que ainda não nasceram. Em segundo lugar, impõem assumir a ligação de todos os seres, acima das coisas,

${ }^{24}$ CAPRA, Fritjof . A teia da Vida. São Paulo: Cul-trix, Brasil. 1996. Nesta obra Capra trata da necessidade e importância do pensamento sistêmico para o meio ambiente como um todo (Teia).

${ }^{25}$ Souza, Maria Claudia da Silva Antunes de. MAFRA, Juliete Ruana. A sustentabilidade e seus reflexos dimensionais na avaliação ambiental estratégica: 0 ciclo do equilíbrio do bem estar. Disponível em: <http:// www.publicadireito.com.br/artigos/?cod=ec82bd533b0033cb> Acesso em: set. de 2014. p. 196.

${ }^{26}$ Souza, Maria Claudia da Silva Antunes de. MAFRA, Juliete Ruana. A sustentabilidade e seus reflexos dimensionais na avaliação ambiental estratégica: 0 ciclo do equilíbrio do bem estar. Disponível em: <http://www. publicadireito.com.br/artigos/?cod=ec82bd533b0033cb> Acesso em: set. de 2014. p. 196.

${ }^{27}$ FREITAS, Juarez. Sustentabilidade: direito ao futuro. Belo Horizonte: Fórum, 2012. p. 31-33. 
e a inter-relação de tudo. De fato, uma das ligações mais significativas das ciências ambientais é de que todas as coisas são interdependentes. Em terceiro lugar, o princípio determina sopesar os benefícios, os custos diretos e externalidades, ao lado dos custos de oportunidade, antes de cada empreendimento.

Conforme Ribeiro e Campos $^{28}$, desenvolver significa crescimento sem prejuízo, sem qualquer tipo de degradação ao ambiente. Portanto, o desenvolvimento já traz implicitamente, em seu bojo, o caráter de sustentabilidade.

Sendo que, o princípio do Desenvolvimento Sustentável (sustainable development) encontra como fundamento o artigo 225 da Constituição Federal de 1988, que prescreve; “Todos têm direito ao meio ambiente ecologicamente equilibrado, bem de uso comum do povo e essencial à sadia qualidade de vida, impondo-se ao Poder Público e à coletividade o dever de defendê-lo e preservá-lo para as presentes e futuras gerações." 29

Por conta disso, vê-se que o desenvolvimento pode se dar, desde que, haja uma gestão racional dos recursos naturais de modo a não comprometê-los, preservando-os para as gerações presentes, como para as futuras. ${ }^{30}$

\section{INSTITUTO DA AVALIAÇÃO DE IMPACTO AMBIENTAL E ESTUDOS DE IMPACTO AMBIENTAL: PRINCIPAIS ASPECTOS JURÍDICOS}

A Avaliação de Impacto Ambiental (AIA), está inserida como instrumento na Política Nacional do Meio Ambiente (PNMA), constituindo, conforme Granziera ${ }^{31}$

Uma das bases de aplicação do art. 170, inciso VI, da Constituição Federal, que condiciona a ordem econômica à defesa do meio Ambiente e consequentemente, aos princípios de prevenção e da precaução. Aplica-se tanto a empreendimentos

\footnotetext{
${ }^{28}$ RIBEIRO, Ana Cândida de Paula; CAMPOS, Arruda. O desenvolvimento sustentável como diretriz da atividade econômica. In Doutrinas Essenciais Direito Ambiental: Fundamentos de Direito Ambiental. Organizadores: MILARÉ, Édis; MACHADO, Paulo Afonso. São Paulo: Revista dos Tribunais. 2011.Vol. 1. p. 648.

29 BRASIL. Constituição. Constituição da República Federativa do Brasil. Brasília, DF: Senado Federal: Centro Gráfico, $1988 . \quad$ Disponível em: <http://www.planalto.gov.br/ccivil_03/constituicao/constituicao.htm> Acesso em: março de 2015.

${ }^{30}$ RIBEIRO, Ana Cândida de Paula; CAMPOS, Arruda. O desenvolvimento sustentável como diretriz da atividade econômica. In Doutrinas Essenciais Direito Ambiental: Fundamentos de Direito Ambiental. Organizadores: MILARÉ, Édis; MACHADO, Paulo Afonso. São Paulo: Revista dos Tribunais. 2011.Vol. 1. p. 649.

${ }^{31}$ GRANZIERA, Maria Luiza Machado. Direito Ambiental. Ed. $3^{\circ}$. São Paulo: Atlas. 2014. p. 406.
} 
de resultados físicos como obras ou resultado, como políticas, projetos e planos. Sujeitam-se à avaliação os projetos públicos ou particulares, industriais ou de outra natureza, em área urbana ou rural, considerada crítica de poluição ou não.

A mesma autora acrescenta o fato de que o princípio 17 da Declaração da Rio /92 estabelece que a Avaliação de Impacto Ambiental, como instrumento nacional, será efetuada para as atividades planejadas que possam vir a ter um impacto adverso significativo sobre o meio ambiente e estejam sujeitas à decisão de uma autoridade nacional competente. ${ }^{32}$

Entende-se, que a AIA, busca analisar, previamente impactos ambientais de quaisquer atividades humanas passíveis de causar danos ao meio ambiente, e à partir daí, buscar soluções para garantir que tais danos não ocorram, sendo que a AIA é gênero, do qual os demais tipos de estudos são espécies. ${ }^{33}$

Considerando que a responsabilidade dos estudos que procedem à Avaliação de Impacto Ambiental é da administração pública, tal atividade somente pode ocorrer mediante um processo administrativo, sendo que o processo é o de licenciamento ambiental. Por conta disso, todas as formas de análises ambientais prévias, definidas pelos regulamentos, devem ser apresentadas pelo empreendedor durante a tramitação do processo dito licenciamento ambiental. ${ }^{34}$

Quanto ao Estudo de Impacto Ambiental (EIA), ou também chamado de Estudo prévio de Impacto Ambiental, é também um dos instrumentos do PNMA, que se relaciona com um segundo instrumento que é o licenciamento ambiental. Conforme dispõe a Resolução $n^{\circ}$ 237/97 do Conselho Nacional do Meio Ambiente (CONAMA), dispõe que atividades lesivas ao meio ambiente devem ser precedidas do EIA e do relatório de impacto sobre o meio ambiente (RIMA). ${ }^{35}$ Impende ressalvar, que conforme o artigo $1^{\circ}$ da Resolução CONAMA $n^{\circ} 1 / 86^{36}$,

Considera-se impacto ambiental qualquer alteração nas propriedades físicas, químicas e biológicas do meio ambiente, causada por qualquer forma de matéria ou energia resultante das atividades humanas que, direta ou indiretamente, afetem a saúde, a segurança e o bem-estar da população, as atividades sociais e econômicas, a biota, as condições estéticas e sanitárias do meio ambiente e a qualidade dos recursos ambientais.

\footnotetext{
${ }^{32}$ GRANZIERA, Maria Luiza Machado. Direito Ambiental. Ed. $3^{\circ}$. São Paulo: Atlas. 2014. p. 406.

${ }^{33}$ GRANZIERA, Maria Luiza Machado. Direito Ambiental. Ed. $3^{\circ}$. São Paulo: Atlas. 2014. p. 407.

${ }^{34}$ GRANZIERA, Maria Luiza Machado. Direito Ambiental. Ed. $3^{\circ}$. São Paulo: Atlas. 2014. p. 408.

35 LEITE, José Rubens Morato. Manual de Direito Ambiental. São Paulo: Saraiva. 2015. p. 246.

${ }^{36}$ GRANZIERA, Maria Luiza Machado. Direito Ambiental. Ed. 3. São Paulo: Atlas. 2014. p. 411.
} 
Ainda, segundo nos Leciona Graziera ${ }^{37}$, com base em Milaré e Benjamin, o EIA, atua fundamentalmente na esfera da discricionariedade da Administração Pública, orientando, informando, fundamentando e restringindo a decisão administrativa. Entretanto, o seu conteúdo, e conclusões não extinguem a apreciação da conveniência e oportunidade que a Administração Pública pode exercer. ${ }^{38}$

\section{A AVALIAÇÃO AMBIENTAL ESTRATÉGICA COMO MODELO DE GESTÃo E SEUS REFLEXOS SOCIAIS}

Constata-se que, não são poucos os casos em que, o dano ao meio ambiente se deve à uma política ambiental anterior, omissa ou insensível quanto aos requerimentos ambientais, a planos e programas de ação que incorrem em falhas ambientalmente graves; e até mesmo a eventuais atos legislativos que não levam em conta as variáveis ambientais necessárias. ${ }^{39}$

Ressalva-se que a Avaliação Ambiental estratégica ainda não tem como produzir efeitos no âmbito jurídico, pois por não estar positivada, não há portanto como ser cobrada essa prática de modo obrigatório. Por isso, trata-se aqui de sua possibilidade jurídica, que entende-se possível. Entretanto, nota-se que no âmbito social produziria efeitos benéficos por ser uma prática que prioriza a prevenção e não a remediação, o que contribui inclusive para um amadurecimento de práticas individuais e coletivas voltadas à proteção ambiental, partindo não somente de uma cobrança pública mas podendo ser inclusive uma cobrança privada.

Daí a necessidade que Milaré nos aponta de proceder uma verdadeira sanatio in radice, a um saneamento do mal em sua raiz. É precisamente este o alvo da Avaliação Ambiental estratégica, desde logo, trata-se de uma forma de avaliação ambiental em pleno sentido. ${ }^{40}$

Este modo de gestão propiciaria, a proteção do meio ambiente em seu modo natural, e não serviria como modo paliativo de tratamento das questões ambientais. O seu diferencial está justamente no seu caráter preventivo. Além de ser esta, um modo de Gestão conscientizador, calcada na precaução, auxiliando inclusive na em uma maior transparência nas análises de obras que imponham risco, por vezes desconhecido ou de difícil mensuração.

\footnotetext{
${ }^{37}$ GRANZIERA, Maria Luiza Machado. Direito Ambiental. Ed. $3^{\circ}$. São Paulo: Atlas. 2014. p. 412.

${ }^{38}$ GRANZIERA, Maria Luiza Machado. Direito Ambiental. Ed. 3 . São Paulo: Atlas. 2014. p. 411.

${ }^{39}$ MILARÉ, Édis. Direito do Ambiente. $9^{\circ}$ Ed. São Paulo: Revista dos Tribunais, 2014. p. 667.

${ }^{40}$ MILARÉ, Édis. Direito do Ambiente. $9^{\circ}$ Ed. São Paulo: Revista dos Tribunais, 2014. p. 667.
} 
Conforme Souza ${ }^{41}$ as avaliações que medem a qualidade e a interferência no meio ambiente tem se demonstrado instrumentos bastante eficazes na busca pela sustentabilidade.

Milaré, nos aponta contribuições no âmbito social, as quais seriam principalmente, para a consecução de um efetivo desenvolvimento sustentável, ressaltando que a monitoração da qualidade ambiental, pressuposto este de qualidade de vida para a sociedade humana, representa um requisito permanente para o direcionamento das políticas ambientais, de modo que a PNMA, consagrou a Avaliação de Impacto Ambiental, por exemplo, como uma ferramenta de gestão. ${ }^{42}$

Entretanto, ainda não está nacionalmente consagrada dentro da PNMA, a Avaliação Ambiental Estratégica, como um meio importante à nível nacional de gestão ambiental.

\section{ANÁLISE DA VIABILIDADE DE IMPLEMENTAÇÃO NO ORDENAMENTO JURÍDICO BRASILEIRO DA AVALIAÇÃO AMBIENTAL ESTRATÉGICA}

Baseando-se no explicitado, sobre os benefícios que a Avaliação Ambiental Estratégica promove na prevenção e precaução concernentes aos impactos provocados ao meio ambiente, há que se proceder com a análise de possibilidade ou não da implementação desta no território brasileiro.

Visto que esta, viabilidade está sendo desenvolvida timidamente em meio a iniciativas regionalizadas, entretanto não há ainda previsão para a $A A E$ à nível de abrangência nacional.

Com relação à experiência brasileira em AAE, vê-se conforme Teixeira ${ }^{43}$, que podem ser identificadas nos anos 1990 , as primeiras iniciativas relacionadas ao tema, entendidas como pontuais e voltadas para atender demandas específicas, principalmente ligadas ao campo energético. Essas experiências são marcadas por uma abordagem baseada na avaliação de impactos de projetos de grande porte.

\footnotetext{
41 SOUZA, Maria Claudia Antunes. Avaliação Ambiental Estratégica: Possibilidades e limites como instrumento de planejamento e de apoio à sustentabilidade. São Paulo: Arraes. 2015. p. 31.

${ }^{42}$ MILARÉ, Édis. Direito do Ambiente. São Paulo: Revista dos Tribunais, 2011. p. 507-509.

${ }^{43}$ TEIXEIRA, I.M.V. O uso da Avaliação ambiental estratégica no planejamento da oferta de blocos para exploração e produção de petróleo e gás natural no Brasil: uma proposta. p. 302. Tese (Doutorado em ciências em planejamento energético) - Universidade Federal do Rio de Janeiro, Rio de Janeiro. 2008. Disponível em: <http://ppe.ufrj.br/ppe/production/tesis/imvieira2.pdf> Acesso em: fev. de 2015.
} 
Após isso, trazem Santos e Souza ${ }^{44}$ que em1994, em virtude da necessidade de obtenção de financiamento por parte do Banco Interamericano de Desenvolvimento (BID) e do Banco Internacional para a Reconstrução e Desenvolvimento (BIRD) o gasoduto Brasil-Bolívia (GASBOL), teve seu projeto inicial submetido a processos de avaliação ambiental para definição e otimização da melhor alternativa de traçado para o duto, visando minimizar os impactos ambientais em áreas sensíveis e evitar áreas urbanas e cidades.

Nota-se que, inclusive houve uma tentativa de institucionalizar a AAE. No ano de 1994 em São Paulo, como consequência de um trabalho de reforma e atualização dos procedimentos de avaliação de impacto ambiental capitaneados pelo Conselho Estadual do Meio Ambiente (CONSEMA). Na ocasião, a Secretaria do Meio Ambiente chegou a aprovar uma resolução criando uma comissão de avaliação ambiental estratégica no âmbito daquela secretaria, mas os trabalhos não obtiveram muitos resultados práticos naquela ocasião, por falta de sincronia entre os órgãos envolvidos. ${ }^{45}$

Nesse ínterim, Souza ${ }^{46}$ nos traz que a $\mathrm{AAE}$, modo de gestão tão importante, ainda não possui legislação específica no Brasil, havendo somente um projeto de Lei, $n^{\circ}$ 4996/2013, que torna a AAE um dos instrumentos da Política Nacional do Meio Ambiente e parte obrigatória do processo de licenciamento ambiental.

Partindo-se dessa lacuna, tem-se que os setores interessados buscam desenvolver o referido instrumento, no entanto, não há parâmetros objetivos claros que possam auxiliar nas diretrizes a serem tomadas nesse sentido. Sendo assim, hoje os gastos com o feitio da Avaliação Ambiental correm por conta do empresariado, e com a implementação deste modo de avaliação, ou seja, com a positivação desta, nasceria a discussão de o Poder Público ter participação nos gastos de estudos para a efetivação da Avaliação Ambiental Estratégica. ${ }^{47}$

Ademais, Alguns órgãos como o Ministério Público Estadual e o Ministério Público Federal, tem buscado a inserção da AAE no Brasil, promovendo Estudos no sentido de

\footnotetext{
${ }^{44}$ SANTOS, Simone Mendonça dos. SOUZA, Marcelo Pereira de. Análise das Contribuições Potenciais da Avaliação Ambiental Estratégica ao plano Energético Brasileiro. Engenharia Sanitária e Ambiental: Revista da Associação Brasileira de Engenharia Sanitária e Ambiental (ABES). Disponível em: < http://dx.doi.org/10.1590/S1413-41522011000400008> Acesso em fev. de 2015.

45 SÁNCHEZ, L.E. (2008). Avaliação Ambiental Estratégica e sua Aplicação no Brasil. Texto preparado como referência para o debate "Rumos da Avaliação Ambiental Estratégica no Brasil", realizado em 9 de dezembro de 2008 no Instituto de Estudos Avançados da Universidade de São Paulo. Disponível em: < http://www.iea.usp.br/iea/aaeartigo.pdf>. Acesso em: fev. de 2015.

46 SOUZA, Maria Claudia Antunes. Avaliação Ambiental Estratégica: Possibilidades e limites como instrumento de planejamento e de apoio à sustentabilidade. São Paulo: Arraes. 2015. p. 35.

47 SOUZA, Maria Claudia Antunes. Avaliação Ambiental Estratégica: Possibilidades e limites como instrumento de planejamento e de apoio à sustentabilidade. São Paulo: Arraes. 2015. p. 35.
} 
aperfeiçoar o Estudo de Impacto Ambiental, buscando aplicar a AAE ante a ausência de instrumento de planejamento eficaz, entretanto, como trata-se de uma lacuna jurídica, não é possível, aplica-la de fato. ${ }^{48}$

Conforme Souza:

[...] no Brasil, as ações estratégicas e complexas, via de regra, envolvem a participação do Estado, seja de forma direta e ativa, seja por meio de grandes financiamentos para grandes obras e empreendimentos, como ocorre no setor energético, de mineração, logística e infraestrutura. Nesse contexto, é de se esperar certa dificuldade ou mesmo resistência de setores governamentais de terem suas atividades controladas por meio de instrumentos de planejamento como o da Avaliação Ambiental Estratégica. [...]

Muitos são os países que adotaram a $\mathrm{AAE}$, em seu modo de gestão socioambiental. Nos Estados Unidos, observa-se que foi criado em 1969 a National Environmental Police Act (NEPA), estabelecendo entre todos os países do globo, a primeira legislação que trata da AAE como conjunto de exigências da Avaliação de Impacto Ambiental. ${ }^{49}$

Já na Europa, houve a Convenção para a Avaliação de Impacto Ambiental Transfonteiriço em, ocorreu na Finlândia em 1991, sendo adotado o acordo no âmbito das Nações Unidas para a Europa, entrando em vigor em 1997. Sendo que mais tarde, em 2001, houve a ratificação por 37 países, onde foi publicado pela Comissão Europeia para Programas e Ações Ambientais, uma espécie de guia para interpretação de "Diretrizes para uma Avaliação Ambiental Estratégica”, onde estabelecia que conforme as necessidades de cada país, individualmente deveriam ser formuladas diretrizes em leis próprias por cada país. ${ }^{50}$

Ademais, na China, pode-se observar que é adotada uma lógica um pouco diferenciada da nossa, porém a Avaliação Ambiental Estratégica, tem seu local de destaque, pois faz parte do sistema de AAE da China a Avaliação de Impacto ambiental, ao contrário da nossa PNMA, que tem a AAE, como modalidade da AIA. Sendo que desde, 2002 foi aprovada a Lei AIA, entrando em vigor em 2003. ${ }^{51}$

\footnotetext{
48 SOUZA, Maria Claudia Antunes. Avaliação Ambiental Estratégica: Possibilidades e limites como instrumento de planejamento e de apoio à sustentabilidade. São Paulo: Arraes. 2015. p. 38.

49 SOUZA, Maria Claudia Antunes. Avaliação Ambiental Estratégica: Possibilidades e limites como instrumento de planejamento e de apoio à sustentabilidade. São Paulo: Arraes. 2015. p. 35.p. 20.

50 SOUZA, Maria Claudia Antunes. Avaliação Ambiental Estratégica: Possibilidades e limites como instrumento de planejamento e de apoio à sustentabilidade. São Paulo: Arraes. 2015. p. 35.p. 21.

51 SOUZA, Maria Claudia Antunes. Avaliação Ambiental Estratégica: Possibilidades e limites como instrumento de planejamento e de apoio à sustentabilidade. São Paulo: Arraes. 2015. p. 35.p. 22.
} 
Portanto, como vê-se em cenário global, em países importantes a Avaliação Ambiental Estratégica já é reconhecida e adotada, assim como cidades, já estão adotando em seu plano diretor, tópicos específicos para a implementação das $\mathrm{AAE}$, como é o caso de São Paulo ${ }^{52}$, o que reforça ainda mais a necessidade de implementação deste modo de gestão, além de que entende-se como viável a implementação desta em nosso país, visto que a mesma não viria à afrontar os outros instrumentos de proteção ambiental, pelo contrário, viria a contribuir com eles.

\section{CONCLUSÃO}

Conclui-se então que a Avaliação Ambiental Estratégica, pode ser tida como um processo, o qual se visa identificar os impactos ambientais de determinado, plano, projeto ou política, visando assim encontrar alternativas que minimizem os danos causados com a implantação de políticas e projetos governamentais.

Esse modo de gestão deve ser utilizado então, na elaboração de propostas dessas ações estratégicas, sistematizando os resultados e sua utilização para tomadas de decisão ambientalmente sustentáveis.

Entretanto, por não estar a Avaliação Ambiental Estratégica positivada em nosso país não é possível que se exija esta prática na formação de políticas, planos, projetos e programas, observa-se ainda com base no exposto, que é possível a implementação desta no ordenamento jurídico brasileiro, havendo como demonstrado Projeto de Lei no sentido de sua implementação e inclusive discussões no sentido que criação de um novo Projeto de Lei.

Além do mais, vê-se que o Brasil, só obteria ganhos com a implementação da AAE, pois, o cenário hoje é de uma cultura onde se perpetua pouco planejamento, baixa transparência e participação social, além de inúmeros casos de corrupção, sendo assim a AAE, serviria como uma medida que revigoraria nossa governança socioambiental, pois visa combater justamente esses erros, como a falta de planejamento, além de ser um avanço, seria uma conquista à mais para o alcance da efetivação da sustentabilidade.

Há, órgãos governamentais, e inclusive órgãos como a Ordem dos Advogados do Brasil, que estão buscando dar visibilidade ao tema e promovendo eventos relacionados a ele, o que por

52 SÃO PAULO. Prefeitura: Plano Diretor. 2013. Disponível em: <http: / /planodiretor.camara.sp.gov.br/wp/wpcontent/files_mf/1386179921Apresentacao_Kazuo241013.pdf > Acesso em: junho de 2015. 
certo, trata avanços na discussão do tema, que tem como objetivo, a implementação da $\mathrm{AAE}$ como um dos importantes instrumentos da Política Nacional do Meio Ambiente.

\section{REFERÊNCIAS}

BASTOS, Diego do Nascimento. A Avaliação Ambiental Estratégica como Subsídio para o Planejamento do Setor de Turismo no Brasil: Uma Análise do Caso da Costa Norte Rio de Janeiro: UFRJ/COPPE, 2010. Dissertação de Mestrado. Orientador: Emilio Lèbre La Rovere Dissertação (mestrado) - UFRJ/COPPE/Programa de Planejamento Energético, 2010 p. 57. Disponível em: <http://www.ppe.ufrj.br/ppe/production/tesis/diego_bastos.pdf> Acesso em: fev. 2015.

BRASIL. Constituição. Constituição da República Federativa do Brasil. Brasília, DF: Senado Federal: Centro Gráfico, 1988. Disponível em:

<http://www.planalto.gov.br/ccivil_03/constituicao/constituicao.htm> Acesso em: março de 2015.

CAPRA, Fritjof . A teia da Vida. São Paulo: Cul-trix, Brasil. 1996.

CENTRO DOM HELDER DE CONVENÇÕES. Gabriel Real Ferrer apresenta palestra sobre as simensões da sustentabilidade. Disponível em: < http://www.ecossocioambiental.org.br/artigos/n-a/>. Acesso em: julho de 2014.

DALAL, Clayton, B.; SADLER, B., Strategic Environmental Assessment: A Sourcebook and Reference Guide to International Experience, London, Earthscan. 2005. Texto disponível em: <http://pubs.iied.org/pdfs/G02193.pdf> Acesso em fev. 2015.

EGLER, Paulo Cezar Gonçalves. Perspectivas de uso no Brasil do Processo de Avaliação Ambiental Estratégica. Brasília: Parcerias Estratégicas, 2001.

FREITAS, Juarez. Sustentabilidade: direito ao futuro. Belo Horizonte: Fórum, 2012.

GRANZIERA, Maria Luiza Machado. Direito Ambiental. Ed. $3^{\circ}$. São Paulo: Atlas. 2014.

LEITE, José Rubens Morato. Manual de Direito Ambiental. São Paulo: Saraiva. 2015.

MILARÉ, Édis. Direito do Ambiente. $9^{\circ}$ Ed. São Paulo: Revista dos Tribunais, 2014.

MILARÉ, Édis. Direito do Ambiente. São Paulo: Revista dos Tribunais, 2011.

IPEA. Objetivos do Milênio. Brasília. 2005. Disponível em:

<http://www.objetivosdomilenio.org.br/> Acesso em: set. de 2014.

ORTOLANO, L.; SHEPHERD, A. apud BUCKLEY, Ralf. Strategic environmental assessment for the new century. Fargo (ND EUA): The Press, 1998. p. 77-86. Disponível em: <http://ac.elscdn.com/S0195925596000716/1-s2.0-S0195925596000716-main.pdf?_tid=7d5beee0-21cc-11e5871c-00000aacb35d\&acdnat=1435959966_654031c38875861d6eef2d242d22a9cf>. Acesso em: julho de 2014. Tradução Livre extraída do artigo Souza, Maria Claudia da Silva Antunes de. 
ANÁLISE SOBRE A APLICABILIDADE DA AVALIAÇÃO AMBIENTAL ESTRATÉGICA NA CONSECUÇÃO DO DESENVOLVIMENTO SUSTENTÁVEL.

Maria Claudia Silva ANTUNES de SOUZA JÉSSICA LOPES FERREIRA BERTOTTI

MAFRA, Juliete Ruana. A sustentabilidade e seus reflexos dimensionais na avaliação ambiental estratégica: 0 ciclo do equilíbrio do bem estar. Disponível em:

<http://www.publicadireito.com.br/artigos/?cod=ec82bd533b0033cb> Acesso em: set. de 2014. PARTIDÁRIO, M. R. Conceitos, evolução e perspectivas da Avaliação Ambiental Estratégica. In: Seminário de Especialistas em Avaliação Ambiental Estratégica na América Latina e na Formulação e Gestão de Políticas. Santiago do Chile: Chile.

RIBEIRO, Ana Cândida de Paula; CAMPOS, Arruda. O desenvolvimento sustentável como diretriz da atividade econômica. In Doutrinas Essenciais Direito Ambiental: Fundamentos de Direito Ambiental. Organizadores: MILARÉ, Édis; MACHADO, Paulo Afonso. São Paulo: Revista dos Tribunais. 2011.Vol. 1.

SÁNCHEZ, L.E. (2008). Avaliação Ambiental Estratégica e sua Aplicação no Brasil. Texto preparado como referência para o debate "Rumos da Avaliação Ambiental Estratégica no Brasil", realizado em 9 de dezembro de 2008 no Instituto de Estudos Avançados da Universidade de São Paulo. Disponível em: < http://www.iea.usp.br/iea/aaeartigo.pdf>. Acesso em: fev. de 2015.

SANTOS, Simone Mendonça dos; SOUZA, Marcelo Pereira de. Análise das Contribuições Potenciais da Avaliação Ambiental Estratégica ao plano Energético Brasileiro. Engenharia Sanitária e Ambiental: Revista da Associação Brasileira de Engenharia Sanitária e Ambiental (ABES). Disponível em: < http://dx.doi.org/10.1590/S1413-41522011000400008> Acesso em fev. de 2015.

SÃO PAULO. Prefeitura: Plano Diretor. 2013. Disponível em:

<http://planodiretor.camara.sp.gov.br/wp/wp-

content/files_mf/1386179921Apresentacao_Kazuo241013.pdf > Acesso em: junho de 2015.

SENADO FEDERAL. Da Conferência das Nações Unidas para o Meio Ambiente Humano, em Estocolmo, à Rio-92: agenda ambiental para os países e elaboração de documentos por Comissão Mundial sobre Meio Ambiente e Desenvolvimento. Revista em discussão. Disponível em: http: //www.senado.gov.br/noticias/Jornal/emdiscussao/rio20/a-rio20/conferencia-das-nacoesunidas-para- o-meio-ambiente-humano-estocolmo-rio-92-agenda-ambiental-paises-elaboracaodocumentos-comissao- mundial-sobre-meio-ambiente-e-desenvolvimento.aspx. Acesso em: julho de 2014.

SILVA, Monica Maria Pereira. Gestão ambiental e desenvolvimento sustentável. 2009.

Disponível em: <http://mercadoetico.terra.com.br/arquivo/gestao-ambiental-edesenvolvimento-sustentável/> Acesso em: julho de 2014.

SOUZA, Maria Cláudia da Silva Antunes de (Org.); GARCIA, Denise Schmitt Siqueira (Org.); FERRER, Gabriel Real [et. al]. Direito ambiental, transnacionalidade e sustentabilidade. Livro eletrônico. Modo de acesso: World Wide Web: <http://www.univali.br/ppcj/ebook>1. ed. Itajaí: UNIVALI, 2013.

SOUZA, Maria Cláudia da Silva Antunes de Souza. 20 anos de sustentabilidade: reflexões sobre avanços e desafios. Revista da Unifebe. 2012; 11 (dez): 239-252. Disponível:

http://www.unifebe.edu.br/revistaeletronica/. Acesso em julho de 2014. 
SOUZA, Maria Cláudia da Silva Antunes de. MAFRA, Juliete Ruana. A sustentabilidade e seus reflexos dimensionais na avaliação ambiental estratégica: 0 ciclo do equilíbrio do bem estar. Disponível em: <http://www.publicadireito.com.br/artigos/?cod=ec82bd533b0033cb > Acesso em: set. de 2014.

TEIXEIRA, I.M.V. O uso da Avaliação ambiental estratégica no planejamento da oferta de blocos para exploração e produção de petróleo e gás natural no Brasil: uma proposta. p. 302. Tese (Doutorado em ciências em planejamento energético) - Universidade Federal do Rio de Janeiro, Rio de Janeiro. 2008. Disponível em:

<http://ppe.ufrj.br/ppe/production/tesis/imvieira2.pdf> Acesso em: fev. de 2015.

VIEIRA, Germano Luiz Gomes. Proteção ambiental e instrumentos de avaliação do Ambiente. Belo Horizonte: Arraes Editores, 2011.

Recebido em: 24/09/2015 / Revisões requeridas em: 23/10/2015 / Aprovado em: 04/11/2015 